by the tumor mass, such as anterior pituitary dysfunctions, visual field alterations, cephalalgia and ophthalmoplegia $^{1-4}$, the last two present in this patient. The association of ophthalmoplegia and cephalalgia is described as a sign of probable metastasis ${ }^{5}$.

Pituitary metastases are rare, but should be included in the differential diagnosis of invasive sellar lesions, especially if associated with ophthalmoplegia, ptosis and DI.

\section{REFERENCES}

1. Komninos J, Vlassopoulou V, Protopapa D, et al. Tumors metastatic to the pituitary gland: case report and literature review. J Clin Endocrinol Metab 2004;89:574-580.

2. Fassett DR, Couldwell WT. Metastases to the pituitary gland. Neurosurg Focus 2004;16:E8.

3. Hoellig A, Niehusmann P, Flacke $S$, Kristof RA. Metastasis to pituitary ade- noma: case report and review of the literature. Cen Eur Neurosurg 2009; 70:149-153.

4. Bhatoe HS, Badwal S, Dutta V, Kannan N. Pituitary metastasis from medullary carcinoma of thyroid: case report and review of literature. J Neurooncol 2008;89:63-67.

5. Morita A, Meyer FB, Laws ER Jr. Symptomatic pituitary metastases. J Neurosurg 1998;89:69-73.

\section{METÁSTASE HIPOFISÁRIA DE ADENOCARCINOMA}

Neuroendocrinology Center of Santa Casa de Porto Alegre, Universidade Federal de Ciências da Saúde de Porto Alegre, Porto Alegre RS, Brazil.

Correspondence: Carolina Garcia Soares Leães - Rua Faria Santos, 142 - 90670 150 Porto Alegre RS - Brasil. E-mail: dracarolina@cisa.med.br

Conflitcs of interest: The authors report no conflict of interest

Received 23 May 2011, received in final form 28 June 2011. Accepted 6 July 2011

\title{
Seizure-like activity during etomidate-modified Wada test interfere with the evaluation of cognitive functions?
}

\author{
Pedro André Kowacs ${ }^{1}$, Tobias Alécio Mattei² , Carlos Rodrigo Goulart², \\ Samantha F. Blattes da Rocha ${ }^{3}$, Ricardo Ramina ${ }^{4}$, Cristiane A. Simão ${ }^{3}$, Murilo Sousa de Meneses ${ }^{5}$
}

The intracarotid amobarbital procedure (IAP), known as "Wada-test" is a useful tool in the investigation of patients who are candidates for temporal lobectomy or amygdala-hippocampectomy. Etomidate is a viable alternative to amobarbital. However, may induce epileptiform activity. We report on the emergence of irritative activity in epilepsy surgery candidates, during a modified Wada procedure using etomidate, and discuss this finding based on available literature ${ }^{1-4}$.

\section{CASE}

Case 1 - 35-year-old female with uncontrolled secondarily generalized seizures since the age of 14 years. Her magnetic resonance images (MRI) revealed right hippocampus sclerosis, and her video-EEG disclosed left-sided temporal interictal intermittent delta activity (TIRDA) and spiking, and an epileptogenic zone at the anterior aspects of the left temporal lobe. On the e-SAM shortly after etomidate injection on the right internal carotid artery there was slowing of the EEG tracing on the right hemisphere, associated with repetitive rhythmic sharp theta activity (Fig 1A). The patient remained hemiplegic on the contralateral side for four minutes, and the EEG recovered its original features 1.5 minutes after motor strength recovery (Fig 1B). When the study was performed on the left side the same abnormal features on EEG tracing were observed right after injection (Fig 1C). Memory and language cognitive tests were performed on both sides under abnormal EEG tracings and there were no signs of compromise of the neuropsychological evaluation as a consequence of the observed irritative EEG activity triggered by etomidate.

Case 2 - A 58 years-old female, suffered from seizures since the age of 34 years. Her MRI had disclosed a right-sided hippocampus sclerosis. An interictal SPECT had revealed a left temporal lobe hypoperfusion. Her Video-EEG recordings showed a right temporal interictal intermittent delta activity, and the recorded seizures revealed an anterior right temporal lobe epileptogenic zone. After etomidate injection on the left side, a slowing of the EEG background activity with associated TIRDA activity ensued on the ipsilateral hemisphere (Fig 2A). The patient remained hemiplegic on the contralateral side and aphasic for 7.5 minutes. Her EEG tracing, however, remained abnormal for a further minute after motor strength and speech normalization. When etomidate was injected in the right side an ipsilateral irritative activity was observed (Fig 2B) and remained during the 

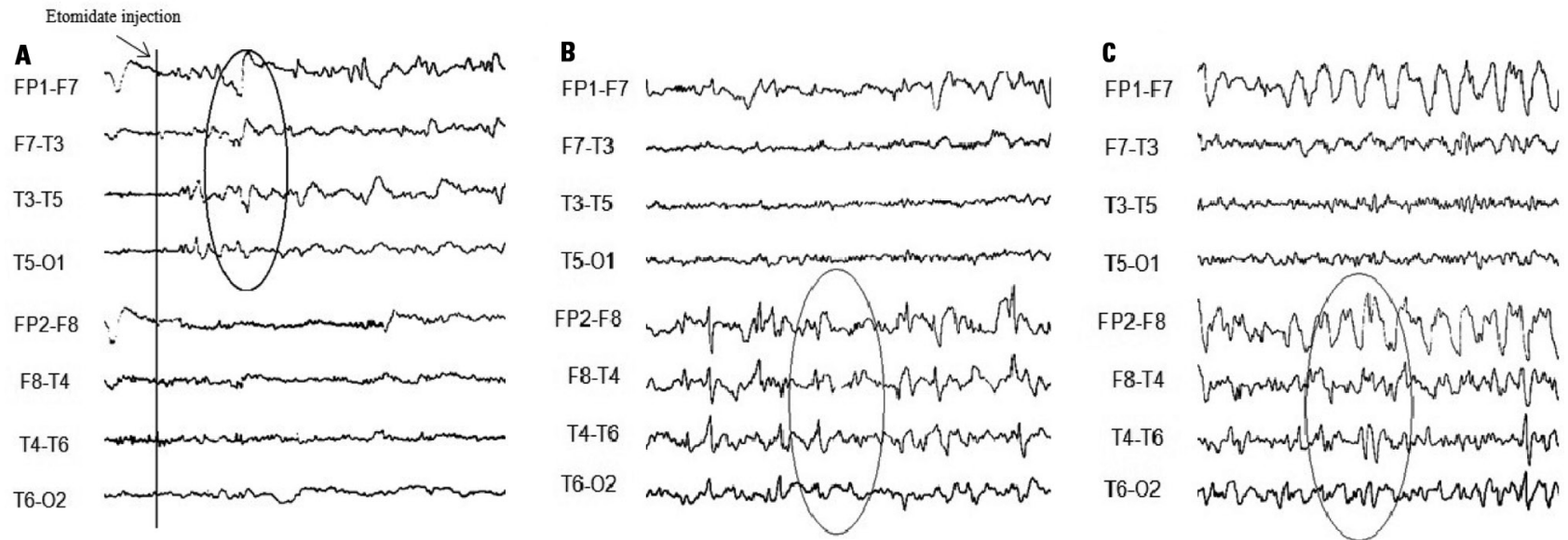

Fig 1. [A] Shortly after etomidate injection on the right internal carotid artery there was slowing of the EEG tracing on the right hemisphere, associated with repetitive rhythmic sharp theta activity. [B] The EEG recovered its original features 1.5 minutes after motor strenght recovery. $[C]$ The study performed on the left side presented with the same abnormal features on EEG tracing observed in right side after injection.
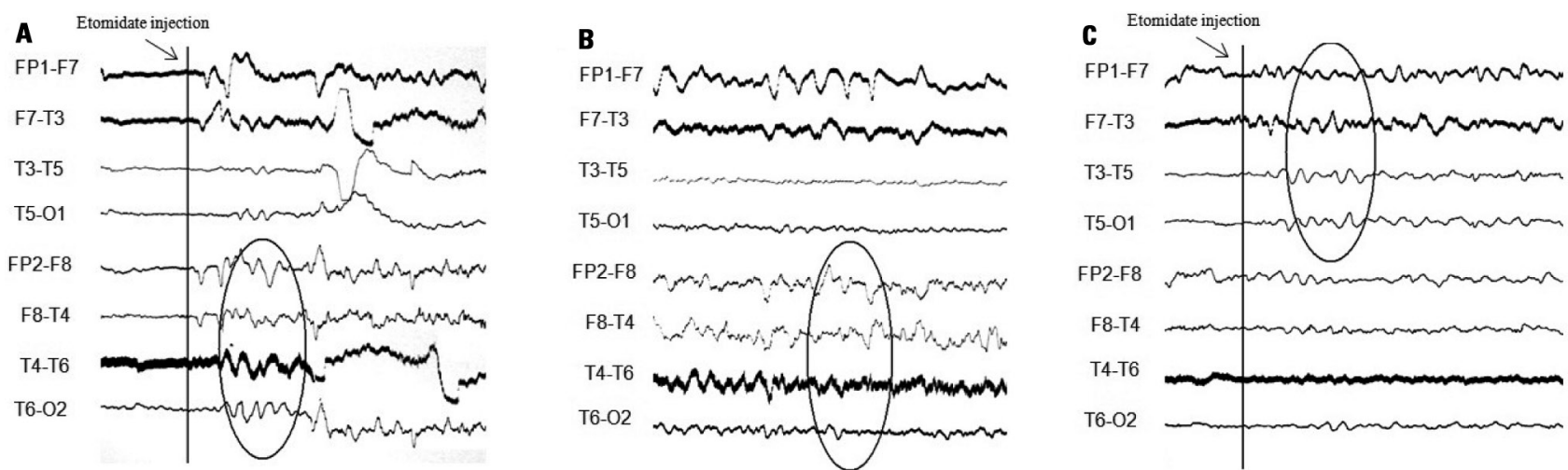

Fig 2. [A] After etomidate injection on the left side, a slowing of the EEG background activity with associated TIRDA activity ensued on the ipsilateral hemisphere has ocurred. [B] The EEG tracing remained abnormal for a further minute after motor strenght and speech normalizaition. [C] When etomidate was injected in the right side and ipsilateral irritative activity was observed and remained during the period of hemiplegia

period of hemiplegia (Fig 2C) The patient recovered his motor strength 7.5 minutes after the injection, with normalization of EEG tracing.

Memory and language cognitive tests were performed on both sides under abnormal EEG tracings and there were no signs of compromise of the neuropsychological evaluation due to the observed irritative EEG modifications caused by etomidate.

\section{DISCUSSION}

Cognitive effects of Subclinical EEG discharges It seems that the abnormal modified eSAM-related theta activity described above does not interfere with the evaluation of memory and language during the test, unless associated seizure-like phenomena occurs. However, further recordings will be of benefit to reveal the real impact on neuropsychological evaluation of cognitive functions ${ }^{2-4}$.

The use of EEG monitoring during the procedure must be encouraged, to facilitate the interpretation of the nature of transient cognitive impairment and/or seizure likephenomena that may eventually occur during the test ${ }^{4,5}$.

\section{REFERENCES}

1. Aldenkamp AP, Arends J. Effects of epileptiform EEG discharges on cognitive function: is the concept of "transient cognitive impairment" still valid? Epilepsy Behav 2004;5(Suppl 1):S25-S34.

2. Reynolds DS, Rosahl TW, Cirone J, et al. Sedation and anesthesia mediated by distinct GABA(A) receptor isoforms. J Neurosci 2003;23:8608-8617.

3. Jones-Gotman M, Sziklas V, Djordjevic J, et al. Etomidate speech and memory test (eSAM): a new drug and improved intracarotid procedure. Neurology 2005;65:1723-1729.

4. Joshi S, Wang M, Etu J, Nishanian EV. Comparison of intracarotid anesthetics for EEG silence. J Neurosurg Anesthesiol 2006;18:112-118.

5. Blattes da Rocha SF, Meneses MS, Kowacs PA, Simão CA, Larocca H, Hunhevicz SC. O Methohexital sódico (Brevital) no teste de Wada: relato de dois casos. J Epilepsy Clin Neurophysiol 2005;11:87-90.

CONSIDERACÕES ACERCA DO POSSÍVEL EFEITO DA ATIVIDADE EPILEPTIFORME DURANTE "TESTE DE WADA MODIFICADO COM ETOMIDATO" SOBRE A AVALIAÇÃO DAS FUNÇÕES COGNITIVAS

Neurology Institute of Curitiba, Curitiba PR, Brazil: ' $C h i e f$ of Neurology Department; ${ }^{2}$ Neurosurgery Department; ${ }^{3}$ Psychology Department; ${ }^{4}$ Chief of Neurosurgery Department; ${ }^{5}$ Chief of Epilepsy Surgery Department.

Correspondence: Tobias Alécio Mattei - Rua Jeremias Maciel Perretto 300 81210-310 Curitiba PR - Brasil. E-mail: tobiasmattei@yahoo.com

Received 14 February 2011, received in final form 21 June 2011. Accepted 29 June 2011 